\title{
Nurse education and the development of the nursing associate role
}

\author{
Emeritus Professor Alan Glasper, from the University of Southampton, discusses the recently launched \\ curriculum for nursing associates and what this might mean for the delivery of care
}

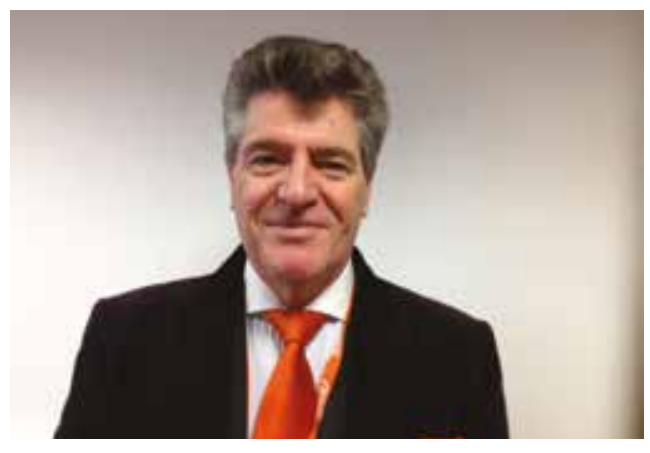

$\mathcal{1}$

n November 2016 Health Education England (HEE) published its Nursing Associate Curriculum Framework (HEE, 2016). The curriculum framework has been designed for those partnerships involved in planning, designing and delivering the new level 5 nursing associate education and training programmes leading to a foundation degree.

NHS England has already commissioned 11 partnership sites to deliver the first of these foundation degrees for 1000 nursing associates, who began their courses in December 2016.

These 11 partnerships, made up of a wide range of NHS trusts and universities, cover the full spectrum of care delivery similar to that of the existing Nursing and Midwifery Council's (NMC's) fields of practice with, for example, Great Ormond Street Hospital for Children in London linking with London South Bank University to offer a foundation degree where the focus is on the care of children, young people and their families.

People who successfully complete the new nursing associate programme will be employed at band 4 but may if they wish subsequently complete a nursing degree.

Although this initiative to remove the glass ceiling that has stymied the career of many healthcare assistants (HCAs) has wide support, the Royal College of Nursing ( $\mathrm{RCN}$ ) has expressed concern about the speed of its implementation (RCN, 2016a).

The RCN has concerns about how the NHS, which is under significant financial pressure, will deploy the new staff grade. There are fears that registered, graduate nurses may be substituted with support staff who do not have the same level of education and experience.

These fears come in the wake of research by Aiken et al (2016), which indicates that the replacement of registered nurses with lower-skilled nursing assistants increases the risk of patient death. The results of this European study found that for every 25 patients, substituting just one professional nurse increased the odds of dying in a hospital with average nurse staffing levels and skill mix by $21 \%$. The RCN believes that the evidence from this study is sufficiently strong to warrant concerns that, without the right number of registered, graduate nurses, patient care may be adversely affected (RCN, 2016b).

As the first of the nursing associates have not yet completed their courses, further research will clearly be necessary to determine their contribution to skill mix and care delivery outcomes.

\section{Background}

Nursing skill mix is as old as the profession itself. Despite the Nurses Registration Act being passed in December 1919, only 12097 nurses were registered with the General Nursing Council (GNC) by 1923 (Glasper and Charles Edwards, 2002). To put this into context, in 2015, there were 314966 qualified nursing staff and health visitors, 25418 midwives, and 23066 GP practice nurses providing care within the NHS (NHS Confederation, 2016).

Clearly the vast majority of care following the Nurses Registration Act would have been delivered by non-registered nursing staff. Indeed, the skill mix of registered to nonregistered nurses was a thorny issue for both the government and the RCN for much of the 1930s and 1940s. An RCN-sponsored inquiry led to the creation of the enrolled nurse in 1942. This initiative was introduced because of an over-reliance by hospitals on untrained nursing auxiliaries and it paved the way for the introduction of the assistant nurse who was to be subsequently enrolled on the GNC register. Subsequently, all assistant nurses had to undergo an approved 2-year course of training and be assessed for competence by the GNC (now the NMC). Enrolled nurse training was eventually configured to facilitate the award of a qualification in general nursing, mental health and learning disability nursing. In many respects the enrolled nurse (nursing assistant) was the predecessor of today's nursing associate, itself born out of concerns about skill mix, shortages of registered nurses and the education and training of HCAs (Glasper, 2016)

Campaigns to elevate the academic basis of nursing and the abolition of the apprenticeship-type training for student nurses gathered pace in the wake of the introduction of the first nursing degree courses in UK universities in the 1960s. By the 1980s it was clear that the enrolled nurse grade would be phased out with the coming of Project 2000, an initiative to make nursing students supernumerary in the workplace. Project 2000 paved the way for the transfer of all nursing education into higher education institutions and the gradual phasing out of the enrolled nurse (Carpenter et al, 2012).

The work contribution of the student nurse and the enrolled nurse was replaced by amending the skill mix of qualified nurses and what later became known as HCAs. Many senior nurses at the time, including nurse educators, lamented the passing of the enrolled nurse as they believed that this second-level nurse was an effective component of the overall skill mix of the nursing workforce. Hospitals had to radically enhance the numbers of HCAs to fill the void after the introduction of supernumerary status for student nurses and to replace enrolled nurses. However, as these 
health workers were replaced with HCAs there were many senior nurses who began to believe that the gaps in clinical acumen between the registered nurse/enrolled nurse and the HCA had become too wide. A large percentage of the enrolled nursing population were later helped to undertake conversion courses leading to a first-level nursing qualification.

\section{Nursing courses}

Registered first-level nurses who trained before Project 2000 were nominally ascribed a level 4 qualification, better known as a higher education certificate. Enrolled nursing qualifications were not awarded any higher education accreditation. The subsequent Project 2000 courses were on the whole approved by universities as level 5 diploma courses, with some later courses being upgraded to the level of advanced diploma, based on their integration of some level 6 credits. Level 6 university courses are normally associated with the acquisition of a degree-level qualification. By 2013 all English universities were able to offer only degreelevel nurse training. This happened earlier in the other countries of the UK (Gov.uk, 2016).

The new nursing associate foundation degrees, which equate to 2 years of full-time study, are level 5 courses. It is important to stress that this new qualification is the same academic level as the previous first-level registered nurse. When they qualify, the new nursing associate 'graduates' will have a higherlevel academic qualification than many existing registered nurses.

\section{The nursing associate curriculum}

HEE aspires to see nursing associates taking a significant role in the provision of effective patient care and in the management and administration of medicines. They will be trained to work independently, within clear demarcations under the supervision of registered nurses and to deliver care according to the agreed patient care plan (HEE, 2016).

HEE has designed a curriculum that provides an education for nursing associates across eight specific domains, namely:

- Professional values and parameters of practice: students will be taught to work independently within defined parameters of practice, where the emphasis will be on clinical and care skills acquisition

- Person-centred approaches to care: in this domain students will be taught how to deliver those skills, attitudes and behaviours that are supportive to the planning, delivery and evaluation of highquality holistic care to patients

- Delivering care: here students will be enabled to work across organisational boundaries and across a range of healthcare environments to deliver clinical and care skills appropriate to their selected area of practice

- Communication and interpersonal skills: in this domain students will be instructed on how to communicate effectively with all members of the interprofessional and multi-agency teams to foster the delivery of holistic care that embraces the '6Cs' that underpin Compassion in Practice: care, compassion, competence, communication, courage and commitment

- Duty of care, candour, equality and diversity: here students will acquire those principles that underpin care, but especially the importance of candour and the ability to be open, honest and transparent with service users when things go wrong with care and treatment and in the provision of truthful information

- Supporting learning and assessment in practice: students will acquire lifelong learning skills in addition to developing supportive roles for others in training

- Team-working and leadership: students will be given tuition on leadership and team working in order to maximise their abilities to fulfil their roles

- Research, development and innovation: students will be taught research awareness and, importantly, the role of evidencebased practice in the delivery of care and in the quest for optimum patient safety.

Trainee nursing associates will be expected, over the 2 years of their programme, to devote approximately $50 \%$ of their time to structured learning activities to address the key learning outcomes within the eight domains.

\section{Conclusion}

Despite the demise of the enrolled nurse in the UK nearly 25 years ago, the assistant/ associate nurse lives on and thrives in other western countries, such as the USA, Canada, Australia and Germany, working under the direction and supervision of registered nurses.

However, suspicions prevail that the new English associate nurse might somehow be used as a replacement for the registered nurse. There will be some who think that the

\section{KEY POINTS}

- The introduction of Project 2000 in the early 1990s paved the way for the transfer of all nursing education into the university sector and the gradual phasing out of the enrolled nurse

- In November 2016 Health Education England published its nursing associate curriculum framework

- The first 1000 nursing associates began their foundation degrees in December 2016 and will take up band 4 positions in early 2019

- Nursing associates will be trained to work under the supervision of registered nurses and to deliver care according to agreed patient care plans

eight domains of the new nursing associate curriculum bear an uncanny resemblance to the registered nurse curriculum of the past.

But perhaps of greater importance is how this new nursing grade will be regulated. HEE has indicated that nursing associates will work to a nationally recognised code of conduct that will be developed during the test phase of the introduction of the Nursing Associate Training Programme. It remains to be seen how this will work in practice when the first cadre of these associates join the nursing workforce in early 2019. BJN

Aiken LH, Sloane D, Griffiths P et al (2016) Nursing skill mix in European hospitals: cross-sectional study of the association with mortality, patient ratings, and quality of care. BMJ Qual Saf https://dx.doi.org/10.1136/bmjqs2016-005567

Carpenter D, Glasper A, Jowett R, Nicholls P (2012) Celebrating 30 years of integrated undergraduate nursing at The University of Southampton, Working Papers in Health Sciences 1(2): 1-6. http://tinyurl.com/z6pltnd

Glasper A (2016) Can a nursing associate role fill the void left by enrolled nurse training? Br J Nurs 25(3): 178-9. https://dx.doi.org/10.12968/bjon.2016.25.3.178

Glasper A, Charles-Edwards I (2002) The child first and always: the registered children's nurse over 150 years. Part two. Paediatr Nurs 14(5): 38-42. https://dx.doi. org/10.7748/paed2002.05.14.4.38.c799

Gov.uk (2016) What qualification levels mean. http:// tinyurl.com/z3nbprs (accessed 4 January 2017)

Health Education England (2016) Nursing Associate Curriculum Framework. 17 November. http://tinyurl.com/ zwfpmsf (accessed 4 January 2017)

NHS Confederation (2016) Key statistics on the NHS. 15 November. http://tinyurl.com/owbegqn (accessed 4 January 2017)

Royal College of Nursing (2016a) RCN responds to nursing associate curriculum. 18 November. http://tinyurl.com/ zsrxlnz (accessed 4 January 2017)

Royal College of Nursing (2016b) Skill-mix risk identified. 15 November. http://tinyurl.com/zn2j7oa (accessed 4 January 2017) 